\title{
Study on Location Choice for NAFFCO Company in Jiangsu Province China
}

\author{
Karim Zakhry (Corresponding author) \\ School of Management, Jiangsu University \\ PO Box 212013, Zhenjiang Jiangsu, China \\ Tel: 86-186-0524-3770Ｅ-mail:k1122770@qq.com \\ Professor Jiang Xin-ying \\ School of Management, Jiangsu University \\ PO Box 212013, Zhenjiang Jiangsu, China \\ Tel: 86-136-0528-3181Ｅ-mail: xinyingj@ujs.edu.cn \\ Mohammed Ismail Alhussam \\ School of Finance and Economics, Jiangsu University \\ PO Box 212013, Zhenjiang Jiangsu, China \\ Tel: 86-187-9608-5361Ｅ-mail: 5103170229@stmail.ujs.edu.cn
}

Received: January 25, 2020 Accepted: February 11, 2020 Published: February 22, 2020

doi:10.5296/ber.v10i1.16510ＵRL: https://doi.org/10.5296/ber.v10i1.16510

\begin{abstract}
The research presents Fuzzy set multi-criteria decision-making approach combined by Delphi method (ADM) to facilitate location decision. Whereas the preference ranking of alternatives importance of the criteria was obtained by (ADM) then obtained the right decision by applying Fuzzy set method. The applicability of the recommended methods was given on NAFFCO firefighting company location selection problem. The importance of this study is that it presented as followed: it is the first usage of the mixed methodologies in the area of location selection (Jiangsu province) that focusing on market size(MS), labor productivity(LP), knowledge $(\mathrm{KN})$, and transportation(T) to facilitate location decision. Second the presented content of methodologies can be used to decide the important weight of
\end{abstract}


the existed variables. Third, reduce the risks that can be faced in making the location decision to gain a fruitful location decision. Fourth, it can be used to facilitate location selection within unlimited locations and unlimited criteria.

Keywords: Fussy set, Delphi, Location decision, FDI, Multi-objective, Jiangsu, Criteria

\section{Introduction}

We live in the age of massive competition and rapid growth. Companies from every nook and corner are struggling to have a sustainable, competitive position and acquisition of the largest market share and getting a global position. One of the most important steps to achieve sustainability and access to the global world market is to create or establish a foreign investment in different geographic dimensions to take the benefit of every place features. Foreign direct investment (FDI) presents an unusual and growing character in global trade. That it can provide the firm with fresh markets and marketing channels, more affordable produce abilities, access to the latest technology, stocks, experiences, and funding. For the hostess country that gets the investment or the international firm, it can present a powerful impetus to economic development(Blaine, 2009). To make a fruitful FDI, Companies need to analyze areas that targeted to find the best location to establish their (FDI) up. The Facility location is and has been a well-established research area within Operations Research (OR). Various articles and writings are observers of this point (Drezner, Klamroth, Schobel, \& Wesolowsky, 2004). The American Mathematical Society (AMS) even formed particular codes for locating obstacles (90B80 for discrete location and assignment, and 90B85 for continuous location). Nonetheless, the subject of the applicability of location types has always been under discussion (Kahraman, Ruan, \& Doğan, 2003). A clear truth that China has become the magnet of foreign investors as the foreign direct investment (FDI) floods into the most populous country and the largest receiver of FDI among emerging countries (Cheng \& Stough, 2006), (WIR, 2012), the United Nations Conference on Trade and Development (UNCTAD) Geneva. The essence of this study will be to facilitate location decision for NAFFCO firefighting Company to make FDI in China Jiangsu province by giving Results and indications for Naffco Company or even similar companies to guide the investing in the right location in terms of knowledge, market size labor productivity, and transportation. By performing fuzzy sets to multiobjective decision making including the appropriate accent on a method of combining varying levels of interest to various objectives and the decision ranking of options value of the criteria was obtained by (ADM). A general location facility included several specific criteria as environment, agglomeration, market size, labor productivity, knowledge, transportation, raw materials. We have chosen the following criteria market size, labor productivity, knowledge, transportation and that was related to studies that emphasized the importance of the formerly mentioned criteria. In our research will find the solutions or the answer to the main question which is what is the best city in Jiang Su province to invest in? And will solve this question by determining the importance of our variables to figure out the perfect city of the targeted location problem. Using fuzzy decision-making approaches Yager's (R. R. J. F. s. Yager \& systems, 1978) weighted goals method to select the best facility location. The rest of this paper organized into four sections as follows. The next section presents the relative literature. Section three presents the data 
and variables. Section four describes the methodology that we will use in our research. Section five results and section 6 concludes.

\section{Literature Review}

Humans are more prone to interference from biasing tendencies if they are forced to provide numerical estimates since the elicitation of numerical estimates forces an individual to operate in a mode that requires more mental effort than that required for less precise verbal statements.

\subsection{Fuzzy Sets Approaches to Facility Location Selection}

(Karwowski, Mital, \& systems, 1986) referred some methods Merged with fuzzy relations are used for dealing quantitatively with imprecision in the word of the weight of each criterion. Yager purposed and presents few concepts about the applicability of fuzzy sets to multi-objective decision making with an appropriate insisting on a means of including various degrees of rank to various objectives(R. R. J. F. s. Yager \& systems, 1978).(Kahraman et al., 2003) referred that Utilization of fuzzy sets indoors the area of decision-making becomes, as one largest part, consisted of extensions While not as decision-making under conditions of risk and uncertainty(R. R. Yager, 1982). There has been growing importance in fuzzy sets to be utilized to the cure location problem in modern times (Kahraman et al., 2003) . Tzeng and Chen state a location model based on a fuzzy multiobjective procedure. The form benefits in settling the optimal quantity and sites of fire stations at an international runway (Tzeng, Chen, \& Technology, 1999). (Kuo, Chi, Kao, \& Engineering, 1999) developed a decision support system using the fuzzy set. (Chen \& systems, 2001) applied a multiple criteria decision-making method for placing distribution stations under fuzzy set.in (Kahraman et al., 2003) the writers sponsor four separate fuzzy multi-attribute location decision-making approaches. weighted goal process and fuzzy AHP offered by (Chang, 1996). All certain procedures are utilized for choosing the best facility location choice by practicing into account both quantitative and qualitative benchmarks. (Xiang-yun \& Zhi-gao, 2006) sponsors fuzzy multiple criteria decision-making process toward choosing the most proper location of reversed logistics reprocessing center. (Gacovski \& Cvetanoski, 2006) states a new multiple criteria decision-making method in order to solve the base station area problem under fuzzy method. (Wu, Lin, Chen, \& Quantity, 2009) additionally uses fuzzy ANP method for deciding the location of a zonal sanatorium in Taiwan. (Bhatia, Dora, \& Jakhar, 2019)evaluate the ideal candidate for location of a remanufacturing plant under fuzzy method.

\subsection{Delphi Method}

HOSSEN believes That Analytic Delphi Method (ADM) is a multicriteria strategic planning model the top management can effectively use to make decisions concerning the location (Azani, Khorramshahgol, \& Economics, 1990). (Cagri Tolga, Tuysuz, Kahraman, \& Making, 2013 ) the writer here used (ADM) to evaluate the criteria of location decision. ADM method will help us to figure out the importance weight of our variables. 


\subsection{Market Size}

Market size is the number of people in a particular market section who are possible buyers. Firms should determine market size before driving new goods or services. The dominant belief is that a wider market the hostess land charms a greater quantum of (FDI). Various observational studies prove that market size is one of the important determinants of (FDI) inflows, especially market-oriented plans of foreign direct investment (Petrović-Ranđelović, Janković-Milić, Kostadinović, \& Organization, 2017). also, Sun and Bomstorm addressed a meaningful size threshold effect for firms' decision to invest overseas.(Blomström \& Lipsey, 1991; Sun, Tong, Yu, \& finance, 2002).

\subsection{Labor Productivity}

Labor productivity is important At a worldwide level, labor productivity, described as the whole output divided by labor inputs.(Samuelson \& Nordhaus, 1989) indicates the extent to which a firm's labor force is efficiently it will create a great output. Organizational results at the usual level; the labor force is a key indicator of workforce achievement.

The U.S. and European investors generally prefer to have their ventures located in the regions with higher labor productivity and better overall economic fundamentals (Zhao \& Zhu, 2000).

\subsection{Transportation}

The transportation of goods, varying from raw supplies to finished goods, is crucial to the economic project and the state of life. It makes the movement of labor feasible, provides economies of scale, and mobilizes Comparable advantages. Freight transport is therefore fundamental for competitiveness (Agenda, 2007).

\subsection{Knowledge}

Knowledge defined as the familiarity, experience, or understanding of someone or something, such as evidence, information, descriptions, or abilities, which is gained through practice or education by grasping, discovering, or learning. Knowledgebase can be defined as a variety of competencies obtained by a person, an institution or a system. Cheung \& Ping, they discovered that science and technical personnel and outgo are the most major determinants of innovation product, as it should be the fact (Cheung \& Ping, 2004). An abundance of knowledge, demand and work sources in a range is very powerful in leading investors' location selection. Besides location choice by enterprises, as knowledge stock (KNOW) market potential (MARKET) and labor sources (LABOR), all have a meaningful real effect. This indicates that the greater the knowledge stock, the more glorious the market potential, and the greater the labor resources of a region (Yu, Shen, \& Management, 2013).

\section{Methodology}

In this research, we use many methods such as Delphi (ADM) Method, Fuzzy sets Method and Maximin approach. 


\subsection{Data and Variables}

Our data are collected mainly from the Annual Report that compiled by the National bureau statistics of China covering.

Our data set has three dimensions:

1. Time dimension, the collected data related the period 2008-2018.

2. Variables dimension knowledge dimension, market size dimension, labor productivity dimension and transportation dimension. our data set cover the following:

Number of various types of professional and technical personnel in terms of determines the knowledge dimension. GDP Growth to determine the market volume where the greater the GDP, the greater the demand potential, market size, and the more enterprises the area will attract (Belderbos, Carree, \& economies, 2002; Cheng \& Stough, 2006; Sun et al., 2002). total output (GDP) divided by labor inputs as an indicator for the labor productivity (Samuelson \& Nordhaus, 1989). Transportation highway in kilometers per square kilometer for a city (Hou \& Zhang, 2001).

Regions dimension, our data will be classified by regions of China. That the data will be classified by regions of China Jiangsu province.

\subsection{DELPHI (ADM) Method}

Delphi method is a forecasting system construction based on the fulfillment of many cycles of surveys sent to a panel of specialists. Here we will use (ADM) to find the Wight of our variables (MS, KN, LP, T) By sending a questionnaire to seven experts from seven several worldwide companies who have years of experiences Several cycles of survey are sent out to this group of experts, and the unknown replies are aggregated and distributed with the group after each round. The experts are left to adapt their answers in the following rounds, based on how they understand the "group acknowledgment" that has been given to them. Since multiple rounds of questions are charged and the panel is shown what the group considers as a whole, the Delphi technique explores to reach the correct response through consensus. When choices which are created by more than oneself are paraded, two varieties from the case of a single decision-maker can be shown: first, the ideas of the self-decision-makers may alter such that each places a different ordering on the options; second, the self-decision-makers may have entrance to various information in which to base their selection(Kahraman et al., 2003). here (ADM) Method can give a decision from individuals as a group decision and without any partiality That shows the importance weight of our variables in pairs to use it in fuzzy sets method That HOSSEN believe That Analytic Delphi Method (ADM) is a multicriteria strategic plan model the top management can efficiently use to make judgments concerning the location (Azani et al., 1990).

\subsection{Fuzzy Sets Method}

The main cause of the use of fuzzy sets in supervising multi-objective is its:

1. The capacity of picture goals. 
2. Useful applications to connecting aims.

3. Practical midpoints of combining various levels of importance to the goals.

If we could give each of the options a number indicative of whereby how powerful it reaches the aims as a "group", we could next choose the option which possesses the greatest rate (R. R. J. F. s. Yager \& systems, 1978).

The advanced system consists of four parts: (1) fuzzy set analytic, (2) importance measurement, (3) data store, and (4) decision-making. We hold a set of choices in our determination

\section{Let $\mathbf{P}$ be the alternatives}

$=\left[P_{1}, P_{2}, P_{3}, P_{4}, P_{5}, P_{6}, P_{7}, P_{8}, P_{9}, P_{10}, P_{11}, P_{12}, P_{13}\right]$

Whereas

Table 1. Presents the thirteen cities in Jiang Su province

\begin{tabular}{|l|l|l|l|l|l|l|}
\hline P1 & P2 & P3 & P4 & P5 & P6 & P7 \\
\hline Nanjing & Wuxi City & Xuzhou & Changzhou City & Suzhou City & Nantong city & Lianyungang City \\
\hline P8 & P9 & P10 & P11 & P12 & P13 & \\
\hline Huai'an city & Salt city & Yangzhou & Zhenjiang & Taizhou City & Suqian City & \\
\hline
\end{tabular}

In our research will possess a distinct purpose $\mathrm{A}$, and will connect it among each state in $\mathrm{P}$ amount $\mathrm{A}[\mathrm{Pi}$ into the interlude $[0,1]$ characteristic of whence great $\mathrm{p}$ convinces goal $\mathrm{A}$, and next marks A as a fuzzy set of P. The advantage of fuzzy sets grew of the truth of representing within aforementioned manner both hazy and fuzzy objectives as strongly as very exactly determined goals.

The aims are designed by the fuzzy sets $=G j, \quad j=1,2,3,4 \ldots m$. the variables.

The value measurement of target $\mathrm{j}$ is shipped by $\mathrm{Wj}$ The achievement of object $\mathrm{Gj}$ through alternative $\mathrm{Pi}$ is represented over the range of association Where $\mathrm{Wj}$ is the membership function of the fuzzy set. The membership value $\mathrm{Wj}$ is a single value within zero and one $[0,1]$ (Gau, Buehrer, \& cybernetics, 1993).

The decision is defined as the intersection of all fuzzy goals, that is:

$$
D=G_{1}^{w 1} \cap G_{2}^{w 2} \cap \ldots \ldots G_{m}^{W m}
$$

And that the best choice is described as gaining the greatest degree of association in $\widetilde{D}(\mathrm{R} . \mathrm{R}$. J. F. s. Yager \& systems, 1978). The measurements were employed being representatives to show the value of an object. The more powerful the value of an aim the greater would be the example of its expressing fuzzy set.

The answer idea can be forwarded as the coming:

Will Give the position $\boldsymbol{P}=\left[\boldsymbol{P}_{\mathbf{1}}, \boldsymbol{P}_{\mathbf{2}}, \boldsymbol{P}_{\mathbf{3}}, \ldots . \boldsymbol{P}_{\mathbf{1 3}}\right]$ including the levels of membership $\mu_{\widetilde{G J}}\left(\boldsymbol{p}_{\boldsymbol{i}}\right)$ 


\section{Macrothink}

of each $\boldsymbol{p}_{\boldsymbol{i}}$ within the fuzzy sets $\widetilde{\boldsymbol{G}}_{\mathbf{j}}$ presenting the aims.

1. Place by pairwise matching the related value, $\boldsymbol{P}_{\boldsymbol{i}}$ of the aims amongst themselves. Arranged the $\boldsymbol{P}_{\boldsymbol{i}}$ in a matrix M.

$$
M=\left[\begin{array}{cccc}
\frac{P_{1}}{P_{1}} & \frac{P_{1}}{P_{2}} & \ldots & \frac{P_{1}}{P_{13}} \\
\frac{P_{1}}{P_{1}} & \frac{P_{2}}{P_{2}} & \ldots \ldots \\
\frac{P_{13}}{P_{1}} & \frac{P_{13}}{P_{2}} & \ldots & \frac{P_{13}}{P_{13}}
\end{array}\right]
$$

2. Discover logical powers $\mathrm{Wj}$ for per object by using Saaty's eigenvector method.

3. Weight the value of object achievement, $\mu_{\widetilde{G_{j}}}\left(\boldsymbol{P}_{\boldsymbol{i}}\right)$ exponentially through the respective $\mathbf{w}_{\mathbf{j}}$. then resulting fuzzy sets would be $\left(\widetilde{G}_{\mathbf{j}}\left(\boldsymbol{P}_{\boldsymbol{i}}\right)\right)^{\mathbf{w j}}$

4. Discover the junction of all $\left(\widetilde{G}_{\mathbf{j}}\left(\boldsymbol{P}_{\boldsymbol{i}}\right)\right)^{\mathbf{w j}}$

$$
\widetilde{D}=\left(\left(x_{i}, \min _{i}\left(\mu_{\widetilde{G J}}\left(x_{i}\right)\right)^{\mathrm{wj}}\right) \quad \mathrm{i}=1 \ldots \mathrm{n} ; \mathrm{j}=1 \ldots \mathrm{m}\right)
$$

5. Choosing $\boldsymbol{P}_{\boldsymbol{i}}$ with greatest value of the fellowship in $\widetilde{D}$ as the best alternative.

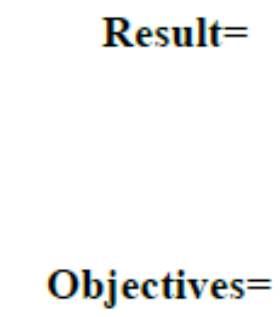

Alternatives $=$

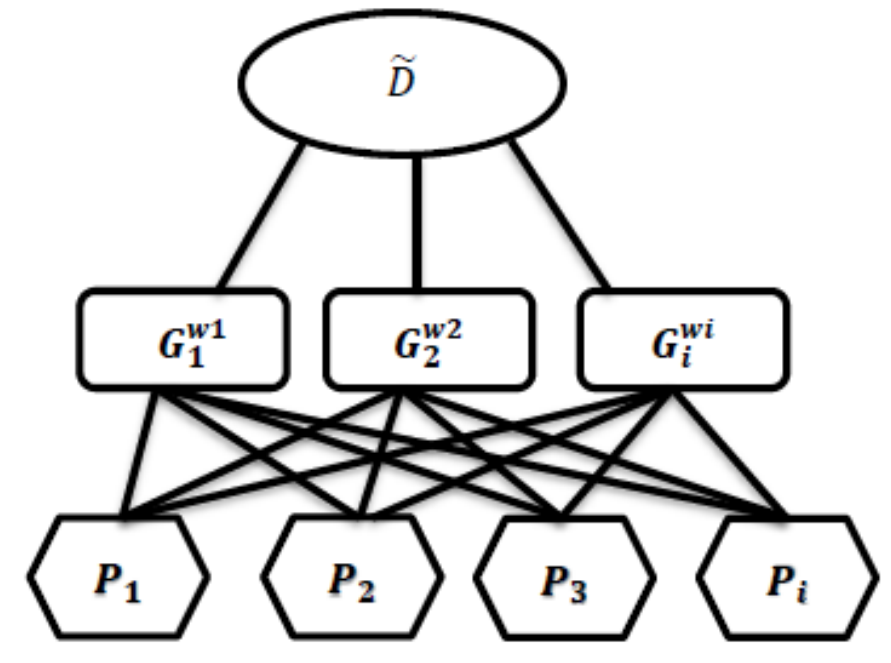

Figure 1. The process of getting the Result

\subsection{Maximin Approach}

The society degree in whole goals owning small weight $(0 \sim 1)$ becomes less. Such holds the result of obtaining the association function of the decision subset $\mathrm{D}$, whereas the min power of every $\mathrm{P}$ over all the goals, living higher chosen over the leading goals. Moreover this procedure performs especially little those options that they imply poor within important goals, accordingly, meanwhile we choose $\mathrm{P} \sim$, that maximizes $\mathrm{D}$ commanded the mean of very unlikely to choose one of certain(Lin \& systems, 2004; R. R. J. F. s. Yager \& systems, 1978).

\section{Results}


The procedure for arranging the value of the weight:

Saaty got generated a system to get the rating scale of value for a collection of $\mathrm{p}$ components based on joined relations(T. L. Saaty \& Khouja, 1976). We will explain it as follows: We asked the decision-maker to connect the goals in joined relations that If we imply comparing aim k with aim c, we select the purposes $a_{k c}$ and $a_{c k}$ as follows:

1) $a_{c k}=1 / a_{k c}$

2) if aim $\mathrm{k}$ is more powerful than aim c so $a_{k c}$ makes selected a figure," as follows:

(If $\mathrm{c}$ is powerful than $\mathrm{k}$, we take the value of $a_{c k}$.)

Table 2. Maximin Approach

\begin{tabular}{|l|l|}
\hline Number & Definition \\
\hline 1 & similar effect \\
\hline 3 & low weight concerning goal above the different goal \\
\hline 5 & powerful weight concerning goal over the different goal \\
\hline 7 & demonstrated weight concerning goal above the different goal \\
\hline 9 & full weight concerning goal above the different goal \\
\hline
\end{tabular}

The magnitude of the importance's power of $a_{k c}$

Saaty (T. J. U. o. P. Saaty, Philadelphia, 1972) has proved that an eigenvector corresponding to the greatest eigenvalue.

$$
\mathrm{W}=\left[\begin{array}{c}
W 1 \\
W 2 \\
\prime \\
W Z
\end{array}\right] \quad \text { Where } \quad A W=\lambda \max \mathrm{w} \quad \sum W k=\mathrm{P}
$$

By presenting the four variables that we have KN, MS, LP, T. We got a comparison of the importance between every two variables for example:

(1) $\mathrm{KN}$ and $\mathrm{T}$ : $\mathrm{KN}$ is more important than $\mathrm{T}$ and the intensity is 5.

(2) MS and LP: MS is more important than LP and the intensity is 7.

(3) LP and T: LP is more important than T and the intensity is 5.

(4) MS and $\mathrm{KN}$ : MS is more important than $\mathrm{KN}$ and the intensity is 5 .

(5) LP and KN: LP is more important than $\mathrm{KN}$ and the intensity is 3.

(6) MS and T: MS is more important than T and the intensity is 9.

After we run (ADM) method and Saaty procedure we got

Table 3. The matrix of subjective attribute weights

\begin{tabular}{|l|l|l|l|l|}
\hline & KN & MS & LP & T \\
\hline KN & 1 & 0.2 & 0.33 & 5 \\
\hline MS & 5 & 1 & 7 & 9 \\
\hline LP & 3 & 0.143 & 1 & 5 \\
\hline T & 0.2 & 0.11 & 0.2 & 1 \\
\hline
\end{tabular}




\section{Mll Macrothink}

Then after conducting it toward the connected maximum eigenvector, we got

$$
\lambda \max =4.389 \text { and } W=\left[\begin{array}{c}
2.932 \\
16.820 \\
4.765 \\
1
\end{array}\right] \quad \text { whereas } \quad \begin{gathered}
\mathrm{MS}=16.82 \\
\mathrm{LP}=4.765 \\
\mathrm{~T}=1
\end{gathered}
$$

The experts saw that MS is the most important that they preferred it strongly more than the rest of our variables and this is consistent with many studies as (Petrović-Ranđelović et al., 2017) .(Belderbos et al., 2002; Blomström \& Lipsey, 1991; Sun et al., 2002) that what we mentioned in market size section above. Whereas MS has a strong affection on FDI and location decision of foreign investment and then it And it was followed by the importance of labor productivity then knowledge then transportation respectively.

In our problem we have thirteen alternatives $\boldsymbol{P}=\left[\boldsymbol{P}_{\mathbf{1}}, \boldsymbol{P}_{\mathbf{2}}, \boldsymbol{P}_{\mathbf{3}}, \ldots . \boldsymbol{P}_{\mathbf{1 3}}\right]$

And four goals, which were represented as fuzzy subsets regarding to $\mathrm{P}$.

$$
\begin{aligned}
K N & =\left[\frac{0.77}{P_{1}}, \frac{0.67}{P_{2}}, \frac{0.92}{P_{3}}, \frac{0.5}{P_{4}}, \frac{1}{P_{5}}, \frac{0.72}{P_{6}}, \frac{0.54}{P_{7}}, \frac{0.47}{P_{8}}, \frac{0.72}{P_{9}}, \frac{0.46}{P_{10}} \frac{0.36}{P_{11}}, \frac{0.49}{P_{12}}, \frac{0.42}{P_{13}}\right] \\
M S & =\left[\frac{0.62}{P_{1}}, \frac{0.61}{P_{2}}, \frac{0.34}{P_{3}}, \frac{0.35}{P_{4}}, \frac{1}{P_{5}}, \frac{0.4}{P_{6}}, \frac{0.13}{P_{7}}, \frac{0.17}{P_{8}}, \frac{0.27}{P_{9}}, \frac{0.26}{P_{10}} \frac{0.22}{P_{11}}, \frac{0.24}{P_{12}}, \frac{0.13}{P_{13}}\right] \\
L P & =\left[\frac{0.96}{P_{1}}, \frac{1}{P_{2}}, \frac{0.50}{P_{3}}, \frac{0.86}{P_{4}}, \frac{0.94}{P_{5}}, \frac{0.62}{P_{6}}, \frac{0.39}{P_{7}}, \frac{0.44}{P_{8}}, \frac{0.42}{P_{9}}, \frac{0.7}{P_{10}} \frac{0.8}{P_{11}}, \frac{0.61}{P_{12}}, \frac{0.34}{P_{13}}\right] \\
T & =\left[\frac{0.78}{P_{1}}, \frac{0.76}{P_{2}}, \frac{0.66}{P_{3}}, \frac{0.95}{P_{4}}, \frac{0.67}{P_{5}}, \frac{1}{P_{6}}, \frac{0.74}{P_{7}}, \frac{0.59}{P_{8}}, \frac{0.52}{P_{9}}, \frac{0.65}{P_{10}} \frac{0.88}{P_{11}}, \frac{0.77}{P_{12}}, \frac{0.56}{P_{13}}\right]
\end{aligned}
$$

And this figure presents the data above:

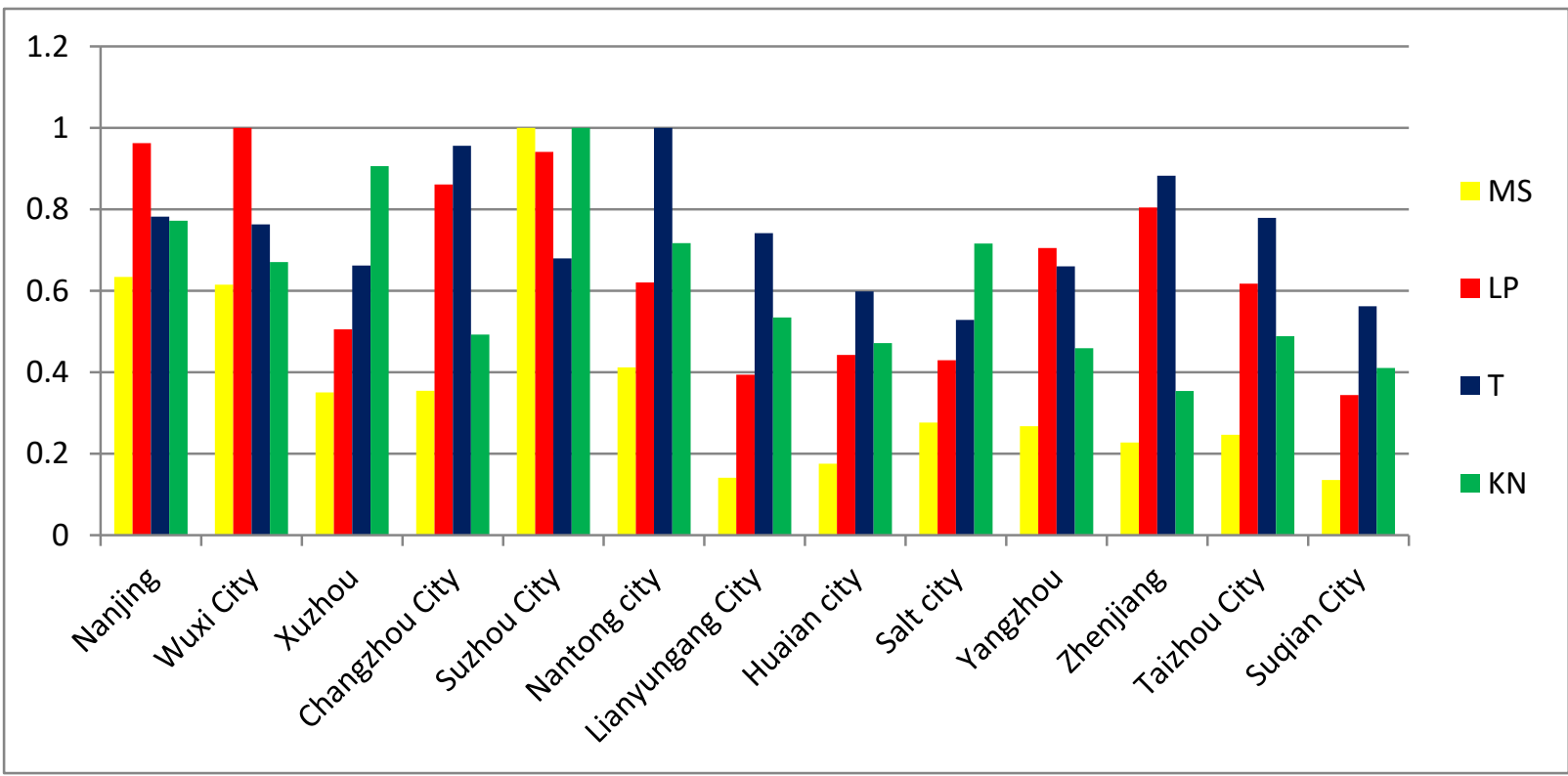

Figure 2. Presenting of the research criteria of Jiang Su province cities

We note that in (1) KN data covering the period between (2014-2018), whereas National 
bureau statistics of China start covering the KN data from 2014. In addition in (2) MS, (3) LP, and (4) $\mathrm{T}$ data covering the period between (2008-2018) the results we obtained were the average of (2008-2018)

We used the average of our data since our study presented to solve the problem of a future decision which is provides more safety.

Furthermore, the relations among the goals are as given in the above sample.

$$
D=G_{1}^{w 1} \cap G_{2}^{w 2} \cap \ldots \ldots G_{m}^{W m}
$$

Which is $G_{N}=$ our variables respectivly and $\mathrm{w}^{\mathrm{n}}=$ is the weight of our variables

$$
\begin{gathered}
D=K N_{1}^{w 1} \cap \boldsymbol{M} \boldsymbol{S}_{2}^{w 2} \cap \boldsymbol{L} \boldsymbol{P}_{3}^{w 2} \cap \boldsymbol{T}_{4}^{w 2} \\
\mathrm{~W}=\left[\begin{array}{c}
2.932 \\
16.820 \\
4.765 \\
1
\end{array}\right]
\end{gathered}
$$

Where is $w^{1}=\mathbf{2 . 9 3 2}, w^{2}=\mathbf{1 6 . 8 2}, w^{3}=\mathbf{4 . 7 6}, w^{4}=1$

Then:

$$
\begin{aligned}
K N & =\left[\frac{0.77}{P_{1}}, \frac{0.67}{P_{2}}, \frac{0.92}{P_{3}}, \frac{0.5}{P_{4}}, \frac{1}{P_{5}}, \frac{0.72}{P_{6}}, \frac{0.54}{P_{7}}, \frac{0.47}{P_{8}}, \frac{0.72}{P_{9}}, \frac{0.46}{P_{10}} \frac{0.36}{P_{11}}, \frac{0.49}{P_{12}}, \frac{0.42}{P_{13}}\right] \\
& =\left[\frac{0.47}{P_{1}}, \frac{0.31}{P_{2}}, \frac{0.80}{P_{3}}, \frac{0.13}{P_{4}}, \frac{1}{P_{5}}, \frac{0.39}{P_{6}}, \frac{0.16}{P_{7}}, \frac{0.11}{P_{8}}, \frac{0.38}{P_{9}}, \frac{0.10}{P_{10}} \frac{0.05}{P_{11}}, \frac{0.13}{P_{12}}, \frac{0.07}{P_{13}}\right]
\end{aligned}
$$

And

$$
\begin{aligned}
& M S=\left[\frac{0.62}{P_{1}}, \frac{0.61}{P_{2}}, \frac{0.34}{P_{3}}, \frac{0.35}{P_{4}}, \frac{1}{P_{5}}, \frac{0.4}{P_{6}}, \frac{0.13}{P_{7}}, \frac{0.17}{P_{8}}, \frac{0.27}{P_{9}}, \frac{0.26}{P_{10}} \frac{0.22}{P_{11}}, \frac{0.24}{P_{12}}, \frac{0.13}{P_{13}}\right]^{16.82} \\
& =\left[\frac{3 \mathrm{E}-04}{\mathrm{P}_{1}}, \frac{2 \mathrm{E}-04}{\mathrm{P}_{2}}, \frac{2 \mathrm{E}-08}{\mathrm{P}_{3}}, \frac{2-\mathrm{E}}{\mathrm{P}_{4}}, \frac{1}{\mathrm{P}_{5}}, \frac{2 \mathrm{E}-07}{\mathrm{P}_{6}}, \frac{4 \mathrm{E}-15}{\mathrm{P}_{7}}, \frac{1 \mathrm{E}-13}{\mathrm{P}_{8}}, \frac{3 \mathrm{E}-10}{\mathrm{P}_{9}}, \frac{1 \mathrm{E}-10}{\mathrm{P}_{10}} \frac{1 \mathrm{E}-11}{\mathrm{P}_{11}}, \frac{4 \mathrm{E}-11}{\mathrm{P}_{12}}, \frac{1 \mathrm{E}-15}{\mathrm{P}_{13}}\right]
\end{aligned}
$$

And

$$
\begin{aligned}
& L P=\left[\frac{0.96}{P_{1}}, \frac{1}{P_{2}}, \frac{0.50}{P_{3}}, \frac{0.86}{P_{4}}, \frac{0.94}{P_{5}}, \frac{0.62}{P_{6}}, \frac{0.39}{P_{7}}, \frac{0.44}{P_{8}}, \frac{0.42}{P_{9}}, \frac{0.7}{P_{10}}, \frac{0.8}{P_{11}}, \frac{0.61}{P_{12}}, \frac{0.34}{P_{13}}\right] \\
& =\left[\frac{0.83}{P_{1}}, \frac{1}{P_{2}}, \frac{0.03}{P_{3}}, \frac{0.48}{P_{4}}, \frac{0.74}{P_{5}}, \frac{0.10}{P_{6}}, \frac{0.01}{P_{7}}, \frac{0.02}{P_{8}}, \frac{0.01}{P_{9}}, \frac{0.18}{P_{10}}, \frac{0.35}{P_{11}}, \frac{0.10}{P_{12}}, \frac{0.006}{P_{13}}\right]
\end{aligned}
$$

And

$$
\begin{aligned}
T & =\left[\frac{0.78}{P_{1}}, \frac{0.76}{P_{2}}, \frac{0.66}{P_{3}}, \frac{0.95}{P_{4}}, \frac{0.67}{P_{5}}, \frac{1}{P_{6}}, \frac{0.74}{P_{7}}, \frac{0.59}{P_{8}}, \frac{0.52}{P_{9}}, \frac{0.65}{P_{10}} \frac{0.88}{P_{11}}, \frac{0.77}{P_{12}}, \frac{0.56}{P_{13}}\right]^{1} \\
& =\left[\frac{0.78}{P_{1}}, \frac{0.76}{P_{2}}, \frac{0.66}{P_{3}}, \frac{0.95}{P_{4}}, \frac{0.67}{P_{5}}, \frac{1}{P_{6}}, \frac{0.74}{P_{7}}, \frac{0.59}{P_{8}}, \frac{0.52}{P_{9}}, \frac{0.65}{P_{10}} \frac{0.88}{P_{11}}, \frac{0.77}{P_{12}}, \frac{0.56}{P_{13}}\right]
\end{aligned}
$$


Then by using Maximin approach will get:

$$
\begin{aligned}
\boldsymbol{D}=[ & \frac{0.00036}{P_{1}}, \frac{0.00027847}{P_{2}}, \frac{1.98368 \mathrm{E}-08}{P_{3}}, \frac{2.18285 \mathrm{E}-08}{P_{4}}, \frac{0.67940236}{P_{5}}, \frac{2.52626 \mathrm{E}-07}{P_{6}}, \frac{4.17 \mathrm{E}-15}{P_{7}} \\
& \left.\frac{1.41291 E-13}{P_{8}}, \frac{3.36273 E-10}{P_{9}}, \frac{1.78027 E-10}{P_{10}}, \frac{1.69943 E-11}{P_{11}}, \frac{4.37746 E-11}{P_{12}}, \frac{1.93832 E-15}{P_{13}}\right]
\end{aligned}
$$

\section{Subsequently}

Our choice would then $(\mathrm{p} 5=0.67940236)$

\section{Conclusion}

The presented paper was applied successfully to a real-international firefighting company the problem of deciding the most desirable location among thirteen alternative cities. This research makes it possible to determine the weights and importance of the criteria. Whereas the Delphi method showed that the market size is the most important variable concerning the decision of a new investment site regarding the studied company. And it was followed by the importance of labor productivity then knowledge then transportation followed by the related weight respectively $16.820,4.7652 .932$, and 1 .

And by impaling the fuzzy sets method Using the weights we obtained from the previous steps by applying them to thirteen cities in Jiangsu Province, the results show that Suzhou city is the best alternative for investing, achieving the best mix of criteria that the experts have considered in importance.

We recommend this research because it applies a new mix of methodologies that can help the company's decision-makers and the experts to get fully understand the essence of their judgment. also one of the useful and powerful implications regarding this research is that the displayed content of methodologies can successfully be used first to decide the important weight of the existed variables second reduce the risk that can be faced in making location decision third it can be used to facilitate location selection within cities, provinces, and even countries to get a clear and right location decision.

\section{References}

Agenda, T. E. s. F. T. (2007). The EU's Freight Transport Agenda: Boosting the Efficiency, Integration and Sustainability of Freight Transport in Europe.

Commission of the European Communities (2007). [Online] Available:

$<$ http://ec.europa.eu/transport/logistics/freight_logistics_action_plan/doc/action_plan/2007_c om_freight_agenda_en.pdf>

Azani, H., Khorramshahgol, R. J. E. C., \& Economics, P. (1990). Analytic Delphi Method (ADM): A strategic decision making model applied to location planning. Engineering Costs \& Production Economics, 20(1), 23-28. https://doi.org/10.1016/0167-188X(90)90005-3

Belderbos, R., \& Carree, M. (2002). The location of Japanese investments in China: Agglomeration effects, keiretsu, and firm heterogeneity. Journal of the Japanese and 
International Economies, 16(2), 194-211. https://doi.org/10.1006/jjie.2001.0491

Bhatia, M. S., Dora, M., \& Jakhar, S. K. (2019). Appropriate location for remanufacturing plant towards sustainable supply chain. Annals of Operations Research, 1-22.

https://doi.org/10.1007/s10479-019-03294-z

Blaine, H. G. (2009). Foreign direct investment.

Blomström, M., \& Lipsey, R. E. (1991). Firm size and foreign operations of multinationals. The Scandinavian Journal of Economics, 93(1), 101-107. https://doi.org/10.2307/3440424

Cagri Tolga, A., Tuysuz, F., \& Kahraman, C. (2013). A fuzzy multi-criteria decision analysis approach for retail location selection. International Journal of Information Technology \& Decision Making, 12(04), 729-755. https://doi.org/10.1142/S0219622013500272

Chang, D.-Y. (1996). Applications of the extent analysis method on fuzzy AHP. European Journal of Operational Research, 95(3), 649-655.

https://doi.org/10.1016/0377-2217(95)00300-2

Chen, C.-T. (2001). A fuzzy approach to select the location of the distribution center. Fuzzy Sets and Systems, 118(1), 65-73. https://doi.org/10.1016/S0165-0114(98)00459-X

Cheng, S., \& Stough, R. R. (2006). Location decisions of Japanese new manufacturing plants in China: a discrete-choice analysis. The Annals of Regional Science, 40(2), 369-387.

https://doi.org/10.1007/s00168-005-0052-4

Cheung, K.-Y., \& Ping, L. (2004). Spillover effects of FDI on innovation in China: Evidence from the provincial data. China Economic Review, 15(1), 25-44.

https://doi.org/10.1016/S1043-951X(03)00027-0

Drezner, Z., Klamroth, K., Schobel, A., \& Wesolowsky, G. (2004). The Weber problem. In Z. Drezner, \& H. W. Hamacher (Eds.), Facility Location. In: Springer, Berlin.

Gacovski, Z., \& Cvetanoski, I. (2006). Fuzzy decision-making for selection of mobile base station location. Paper presented at the 28th International Conference on Information Technology Interfaces. https://doi.org/10.1109/ITI.2006.1708514

Gau, W.-L., \& Buehrer, D. (1993). Vague sets. IEEE Transactions on Systems, Man, and Cybernetics, 23(2), 610-614. https://doi.org/10.1109/21.229476

Hou, J. W., \& Zhang, K. H. (2001). A location analysis of Taiwanese manufacturing branch-plants in mainland China. International Journal of Business, 6(2), 53-66.

Kahraman, C., Ruan, D., \& Doğan, I. (2003). Fuzzy group decision-making for facility location selection. Information Sciences, 157, 135-153.

https://doi.org/10.1016/S0020-0255(03)00183-X

Karwowski, W., \& Mital, A. (1986). Potential applications of fuzzy sets in industrial safety engineering. Fuzzy Sets and Systems, 19(2), 105-120.

https://doi.org/10.1016/0165-0114(86)90031-X 


\section{Ml Macrothink}

Business and Economic Research ISSN 2162-4860 2020, Vol. 10, No. 1

Kuo, R. J., Chi, S. C., \& Kao, S. S. (1999). A decision support system for locating convenience store through fuzzy AHP. Computers \& Industrial Engineering, 37(1-2), 323-326. https://doi.org/10.1016/S0360-8352(99)00084-4

Lin, C.-C. (2004). A weighted max-min model for fuzzy goal programming. Fuzzy Sets and Systems, 142(3), 407-420. https://doi.org/10.1016/S0165-0114(03)00092-7

Petrović-Ranđelović, M., Janković-Milić, V., \& Kostadinović, I. (2017). Market size as a determinant of the foreign direct investment inflows in the Western Balkans countries. Facta Universitatis, Series: Economics and Organization, 14(2), 093-104.

https://doi.org/10.22190/FUEO1702093P

Saaty, T. J. U., \& Philadelphia, P. (1972). Hierarchies, priorities, and eigenvalues.

Saaty, T. L., \& Khouja, M. W. (1976). A measure of world influence. Conflict Management and Peace Science, 2(1), 31-48. https://doi.org/10.1177/073889427600200103

Samuelson, P., \& Nordhaus, W. J. N. Y. (1989). Economics: Business organization. itd: McGraw-Hill.

Sun, Q., Tong, W., \& Yu, Q. (2002). Determinants of foreign direct investment across China. Journal of International Money and Finance, 21(1), 79-113.

https://doi.org/10.1016/S0261-5606(01)00032-8

Tzeng, G. H., \& Chen, Y. W. (1999). The optimal location of airport fire stations: a fuzzy multi-objective programming and revised genetic algorithm approach. Transportation Planning and Technology, 23(1), 37-55. https://doi.org/10.1080/03081069908717638

Wu, C.-R., Lin, C.-T., \& Chen, H.-C. (2009). Integrated environmental assessment of the location selection with fuzzy analytical network process. Quality and Quantity, 43(3), 351-380. https://doi.org/10.1007/s11135-007-9125-z

Xiang-yun, C., \& Zhi-gao, C. (2006). A fuzzy-based location selection method for reverse logistics reprocessing center. Paper presented at the 2006 International Conference on Management Science and Engineering. https://doi.org/10.1109/ICMSE.2006.313956

Yager, R. R. (1982). Fuzzy set and possibility theory: Recent developments, Pergamon.

Yager, R. R. (1978). Fuzzy decision making including unequal objectives. Fuzzy Sets and Systems, 1(2), 87-95. https://doi.org/10.1016/0165-0114(78)90010-6

Yu, S.-H., \& Shen, C. F. (2013). Geographic proximity and location choice of foreign direct investment in China. Asian Business \& Management, 12(3), 351-380.

https://doi.org/10.1057/abm.2013.4

Zhao, H., \& Zhu, G. (2000). Location factors and country-of-origin differences: An empirical analysis of FDI in China. Multinatl Bus Rev, 8(1), 60. 


\section{Copyright Disclaimer}

Copyright for this article is retained by the author(s), with first publication rights granted to the journal.

This is an open-access article distributed under the terms and conditions of the Creative Commons Attribution license (http://creativecommons.org/licenses/by/3.0/). 